\title{
AS DINÂMICAS DAS FRONTEIRAS \\ E AS VÍTIMAS DE HOMICÍDIOS \\ EM FOZ DO IGUAÇU / PR (2001-2010)
}

\author{
THE DYNAMICS OF BORDERS AND \\ VICTIMS OF HOMICIDE IN \\ FOZ DO IGUAÇU / PR (2001-2010)
}

Eric Gustavo Cardin*

RESUMO: Foz do Iguaçu/PR representa uma das cidades brasileiras com os maiores índices de violência contra jovens do Brasil, principalmente quando se observa o número de vítimas de homicídios com menos de 18 anos de idade. A pesquisa realizada e ora apresentada teve como objetivo traçar um perfil das crianças e adolescentes vitimadas, buscando entender suas trajetórias individuais e as dimensões dos processos de socialização. Durante quase dez anos foram acumuladas e organizadas informações obtidas em bancos de dados públicos e por meio de entrevistas realizadas com os responsáveis das vítimas. Os resultados obtidos possibilitam observar o desenvolvimento da problemática, a construção de perfis e uma análise teórica derivada das seguintes constatações: 1) a pobreza corresponde a um elemento comum na maioria dos casos; 2) a presença do poder público por meio de seus aparelhos repressivos e corretivos modifica os índices; 3) o impacto das transformações nos processos de socialização não é nítido e, por fim; 4) as dinâmicas próprias de uma fronteira desigual fomentam um contexto fundamental no entendimento da violência.

Palavras-chaves: violência; segurança pública; fronteiras; saúde coletiva.

\footnotetext{
* Doutor em Sociologia; Professor do Programa de Pós-Graduação em Ciências Sociais da Universidade Estadual do Oeste do Paraná - UNIOESTE, Toledo, PR, Brasil; e-mail: eric_cardin@ hotmail.com
}

155| Século XXI, Revista de Ciências Sociais, v.3, nº 2, p.155-181, jul./dez. 2013 ISSN: 2236-6725 
ABSTRACT: Foz do Iguaçu / PR represents one of the Brazilian cities with the highest rates of violence against young people in Brazil, especially when it comes to the number of homicide victims under 18 years old. This research aimed to determine a profile of children and adolescents victims and understand their individual trajectories and the dimensions of socialization processes. For almost ten years were accumulated and organized information collected in public databases and through interviews with those responsible for the victims. With the results is possible to observe the development of the problem, the construction of the profiles and a theoretical analysis derived from the following findings: 1) poverty corresponds to a common element in most cases; 2) the presence of public power through repressive and corrective actions modifies indexes; 3) the impact of changes in socialization processes is not apparent and, finally; 4) the dynamics of a very uneven border promote a fundamental environment on the understanding of violence.

Keywords: violence, public safety; borders; public health.

\section{INTRODUÇÃO}

Foz do Iguaçu é um município localizado no extremo oeste do Estado do Paraná, com 256.081 habitantes (Foz do Iguaçu, 2011). Sua economia é intimamente atrelada ao setor turístico que, por sua vez, é altamente dependente das visitações ao Parque Nacional do Iguaçu e à Usina Hidrelétrica de Itaipu. Outras importantes fontes de renda estão vinculadas as diversas possibilidades mercantis originadas da existência das fronteiras internacionais com a Argentina e o Paraguai. De modo geral, a região é marcada por uma formação demográfica heterogênea, composta por mais de 70 etnias, e por um grande fluxo de pessoas, capitais e mercadorias, que fomenta um contexto social marcado por dinamismos próprios (Cardin, 2011c).

No entanto, a multiplicidade étnica derivada das migrações, as flutuações do mercado de trabalho, os diferentes ciclos econômicos da cidade e as oportunidades fomentadas pelas fronteiras não vem 
garantindo números positivos referentes ao desenvolvimento social e econômico. Pelo contrario, a cidade é marcada por desigualdades, por concentração de renda, por processos de empobrecimento das condições de habitação e por altos índices de criminalidade. Observa-se, por exemplo, que Foz do Iguaçu possui as maiores taxas de homicídios no Estado do Paraná e se destaca nacionalmente pelos índices relacionados aos números de homicídios juvenis (Waiselfisz, 2011).

Como destaca Kleinschmitt (2012, p.74), desde 1979 as taxas de mortes por homicídio ocorridos no município foram superiores às taxas estaduais e nacionais, atingindo o número de 102 mortes por 100 mil habitantes em 2006. O aumento de mortes por homicídio em Foz do Iguaçu entre 1979 e 2006 foi de aproximadamente 69 óbitos por 100 mil habitantes, com um pico considerável de crescimento entre os anos 2000 e 2003, quando permaneceram elevadas até 2006. Após o ano de 2006, as taxas no município tiveram uma queda considerável chegando a 61 por 100 mil habitantes em 2009. Apesar da diminuição das taxas, o município continua com os indicadores extremamente elevados.

Kleinschmitt (2012, p. 75) observa que a população masculina foi a mais vitimada, pois desde o ano de 1979 os números referentes às mortes de pessoas do sexo masculino sempre acompanharam a tendência geral de crescimento das taxas no município. Neste contexto, enquanto as taxas em 1979 estavam em 33 por 100 mil habitantes, as taxas de mortes do sexo masculino estavam em 27,14. No ano 2009, as taxas apresentavam um índice de 60,59 mortes por 100 mil habitantes, sendo 55,98 compostas pela população masculina. No total das 4.221 mortes por homicídio no município, 3.899 eram de homens. 
Gráfico 01 - Relação Adolescentes Vítimas de Homicídio, Gênero e Ano

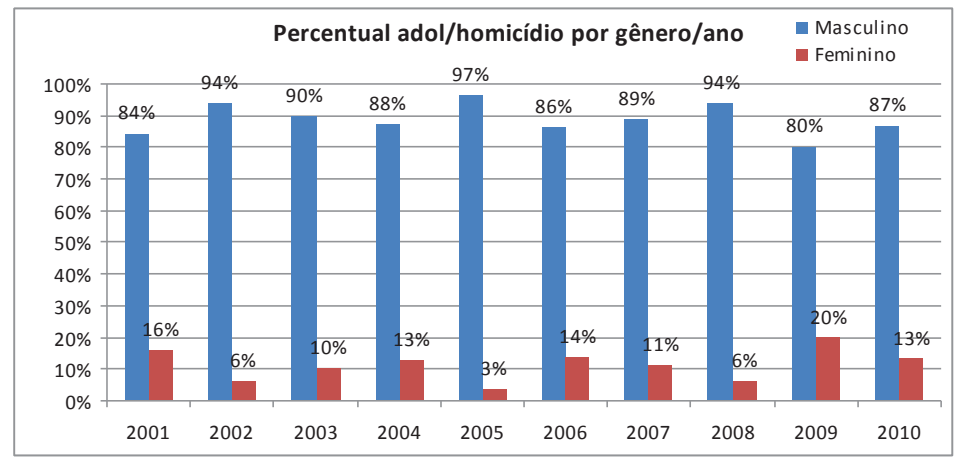

Fonte: Fundação Nosso Lar.

Outro aspecto relevante destacado nos estudos referentes à violência na cidade diz respeito à idade das vítimas. $\mathrm{O}$ maior percentual de óbitos por homicídio foi visualizado na população jovem e adulta, entre 15 e 39 anos de idade, tendência que se repete em todos os lugares do mundo. Contudo, a diferença é a intensidade dessas mortes em Foz do Iguaçu, especialmente na faixa etária de 20 a 29 anos. Até muito recentemente, o município liderava nacionalmente o ranking das localidades com os maiores índices de mortes de jovens e adolescentes no país, apresentando números superiores àqueles apresentados por grandes capitais e por outras cidades fronteiriças, como Ponta Porã e Guaíra (Waiselfisz, 2011).

O problema social descrito, devido ao impacto econômico, político, social e humano, vem exigindo estudos cuidadosos para servir de base à construção de políticas públicas e à intervenção da sociedade civil organizada. Assim, o presente artigo apresenta parte dos resultados de uma extensa pesquisa de acompanhamento sistematizado das questões vinculadas aos números de óbitos de jovens vítimas de homicídios em Foz do Iguaçu. Trata-se de um trabalho coletivo de mais de 10 anos, onde foram analisados bancos de dados públicos e entrevistas realizadas com os familiares ou responsáveis de quase a totalidade das vitimas com idade igual ou inferior a 17 anos.

A investigação foi iniciada no ano de 2004 com o objetivo de identificar a realidade, os motivos e o perfil dos adolescentes aco158| Século XXI, Revista de Ciências Sociais, v.3, nº 2, p.155-181, jul./dez. 2013 ISSN: 2236-6725 
metidos pela violação de seu direito a vida, visando auxiliar ou de algum modo subsidiar o poder público e a sociedade em geral naquilo que se refere aos dados sobre o problema. Os trabalhos realizados tiveram o apoio da Usina Hidrelétrica de Itaipu, da Universidade Estadual do Oeste do Paraná, da Vara da Infância e da Juventude, da Prefeitura Municipal de Foz do Iguaçu, do Instituto Médico Legal, da Central de Lutos, da Vigilância Epidemiológica, da Delegacia de Homicídios e do Governo do Estado do Paraná, com a coordenação geral da Fundação Nosso Lar.

Para tanto, adotou-se a definição de homicídios utilizadas no campo da saúde coletiva, que explicita que a morte violenta provocada por homicídio é conseqüência de golpes, de feridas e de traumatismos resultantes de intervenções exteriores e brutais, podendo ser intencional ou acidentalmente infligidas (Zaluar, 2004). No Artigo 121 do Código Penal Brasileiro homicídio é definido de forma bastante objetiva como "matar alguém”. Para a realização deste estudo, foram excluídos os casos de mortes ocorridas durante os conflitos com a polícia.

As técnicas para obtenção dos dados foram compostas por diversas formas de abordagem. Em um primeiro momento foi realizado um levantamento e cruzamento de dados disponibilizados por órgãos públicos e imprensa: certidões de óbito, laudos cadavéricos, IML, consultas a jornais, dados da Delegacia de Homicídios e da Central de Óbitos. Em um segundo momento foi aplicado um questionário estruturado diretamente a um dos familiares ou responsáveis do adolescente assassinado. Nos anos de 2004 e 2005 as entrevistas eram realizadas diretamente nas residências das vítimas, técnica que permitia uma vivencia diferenciada durante a pesquisa, mas, por outro lado, acarretava alguns transtornos.

Neste sentido, no intuito de garantir a segurança dos pesquisadores, começou-se a enviar correspondência para os endereços contidos nos documentos da Delegacia de Homicídios, do IML e da Central de Lutos, convidando os familiares ou responsáveis a participarem da pesquisa comparecendo, mediante agendamento, ao Fórum de Justiça. As cartas devolvidas e os familiares ou responsáveis que não compareceram da data definida receberam visitas da 
equipe de trabalho, visando atingir a totalidade dos casos ocorridos. O resultado da estratégia adotada foi positivo, pois permitiu a realização de entrevistas com uma parcela significativa da população, abrangendo $66,33 \%$ dos 328 casos.

Tabela 01 - Número de Entrevistas Realizadas

\begin{tabular}{|c|c|c|c|}
\hline Ano & $\begin{array}{c}\text { Total de } \\
\text { adolescentes } \\
\text { vítimas de } \\
\text { homicídio }\end{array}$ & $\begin{array}{c}\text { Número de } \\
\text { questionários } \\
\text { aplicados com } \\
\text { familiares ou } \\
\text { responsáveis }\end{array}$ & $\begin{array}{c}\text { Certidão de óbitos } \\
\text { consultados nos casos } \\
\text { de impossibilidade de } \\
\text { realização da entrevista }\end{array}$ \\
\hline 2001 & 19 & 9 & 10 \\
\hline 2002 & 33 & 16 & 17 \\
\hline 2003 & 29 & 19 & 10 \\
\hline 2004 & 32 & 23 & 9 \\
\hline 2005 & 29 & 29 & 17 \\
\hline 2006 & 51 & 34 & 24 \\
\hline 2007 & 54 & 30 & 12 \\
\hline 2008 & 33 & 21 & 8 \\
\hline 2009 & 25 & 17 & 10 \\
\hline 2010 & 23 & 13 & \\
\hline
\end{tabular}

Fonte: dados da Fundação Nosso Lar organizados pelo autor.

O questionário aplicado era composto por 64 perguntas e abrangia diversas dimensões sociais. De forma geral, ele buscava: 1) traçar um perfil da vítima e de seus pais explorando indicadores econômicos e educacionais; 2) explorar as relações sociais das vítimas e os seus grupos de pertencimento; 3) investigar a aproximação dos adolescentes com o crime organizado e com situações violentas, observando também a existência ou não de passagens da vítima em instituições de recuperação de menores; 4) por fim, observar questões mais pontuais relacionadas aos possíveis motivos do homicídio.

Devido à abrangência do estudo realizado e as inúmeras possibilidades de análise existentes, este artigo irá se concentrar em algumas das observações possíveis de serem realizadas por meio de reflexões sobre o conjunto dos indicadores levantados. Contudo, salienta-se que a pesquisa realizada já possibilitou a publicação do livro "Abandono, Exploração e Morte de Crianças e Adolescentes em Foz do Iguaçu" no ano de 2006, contendo resultados parciais da investigação. Atualmente, encontra-se em estado de elaboração um 160| Século XXI, Revista de Ciências Sociais, v.3, nº 2, p.155-181, jul./dez. 2013 ISSN: 2236-6725 
novo livro composto pela análise geral dos dados coletados no projeto por pesquisadores de diferentes áreas do conhecimento.

\section{A POBREZA E OS GRUPOS DE SOCIALIZAÇÃO DAS VÍTIMAS}

O desenvolvimento econômico de Foz do Iguaçu não é linear ou progressivo. Ele é marcado por ondas bem definidas de crescimento sucedidas por grandes recessões. Em linhas gerais, o governo brasileiro sempre se apresentou de uma maneira determinante nos diferentes ciclos econômicos vivenciados na região. No processo inicial de povoamento, com a criação da Vila Militar e com a conseqüente colonização, durante a construção das pontes internacionais e da Usina Hidrelétrica de Itaipu Binacional e, por fim, no controle estatal dos fluxos de pessoas, capitais e mercadorias nas divisas com a Argentina e o Paraguai.

Os picos de acumulo de capital e de aumento demográfico possibilitado por cada um dos momentos apresentados acima são acompanhados posteriormente de grandes crises, marcadas por aumento do desemprego e da ocupação territorial irregular. Tal situação fomenta uma cidade com um desenho urbano problemático e de difícil planificação, somada a uma péssima distribuição de renda. As conseqüências desta configuração social é uma significativa dependência do município em relação às práticas informais relacionadas a comércio existente em Ciudad del Este, Paraguai (Cardin, 2009a; 2011c).

Segundo Kleinschmitt (2012, p. 100), “efetuadas comparações com Brasil, Paraná, Curitiba, Foz do Iguaçu, Cascavel e Toledo (outros municípios pólo da região) o município acumula indicadores socioeconômicos preocupantes". A autora demonstra que:

os indicadores com piores desempenhos em relação aos outros locais analisados são a "Esperança de vida ao nascer" e a "Longevidade (IDHM-L)". A “Taxa bruta de frequência escolar", a "Educação (IDHM-E)" e o "IDH-M" apareceram na quarta posição, na frente somente dos indicadores do Paraná e do Brasil, ou seja, os números de Foz do Iguaçu só são melhores do que a média do Paraná e do 
país. Os indicadores "Taxa de alfabetização de adultos", "Renda per capita" e "Renda (IDHM-R)" apareceram na terceira posição, atrás somente dos indicadores de Curitiba e Cascavel. Em relação aos indicadores socioeconômicos Foz do Iguaçu está na posição 42 e na classificação nacional em 850.

A pesquisa realizada por Andrade (2009) fortalece o entendimento dos vínculos entre as questões econômicas e os índices de criminalidade da região. Por meio de um cruzamento dos dados apresentados por este autor com informações obtidas em um estudo anterior (Cardin, 2009a), constata-se que os bairros mais populosos e que possuem a renda per capita mais baixa são aqueles que possuem o maior número de homicídios juvenis. Neste sentido, observa-se que no período de 2000 a 2007, as regiões que apresentaram maior concentração de homicídios foram o São Francisco, a Vila C e a Vila Carimã, locais que, "coincidentemente", também apresentam a renda média mais baixa entre os trabalhadores informais. Não suficiente, destaca-se que o local onde ocorreu a agressão, em 67,3\% dos casos, fica a uma distância de no máximo de 1000 metros do local de residência da vítima, o que nos permite afirmar que estes jovens não procuram uma situação de risco, eles vivem no interior dela.

Grande parte das favelas do município está localizada em áreas de invasão, de preservação ambiental, constituídas de moradias insalubres, sem saneamento básico, energia elétrica, e outros e ainda um déficit habitacional que gira em torno de 10 mil unidades. Ainda, de acordo com dados do Plano Diretor do Município, Foz do Iguaçu conta com 10,22\% de pessoas vivendo abaixo da linha da pobreza. (Souza, 2011, p. 01).

Contata-se que mais de 20 mil moradores do município encontram-se abaixo da linha de pobreza. Em linhas gerais, trata-se de uma população pobre, inseridas precariamente na economia e com baixa escolaridade. Concentrando-se em alguns indicadores econômicos dos familiares das vítimas de homicídio em Foz do Iguaçu, observa-se que a renda da maioria das famílias não ultrapassava dois 
salários mínimos e era obtida basicamente por meio do desenvolvimento de atividades precárias e informais, que exigiam uma baixa escolaridade e ofereciam baixos salários. As atividades são as mais diversas, se distribuindo em algumas dezenas de ocupações diferentes, porém algumas se destacam por apresentarem alguma concentração. Entre os pais dos jovens observam-se que 32\% atuavam em alguma atividade vinculada à construção civil ou manutenção predial, $8 \%$ em atividades vinculadas ao Paraguai e 5\% em atividades vinculadas ao circuito turístico da cidade.

Tabela 02 - Ocupação dos Pais das Vítimas

\begin{tabular}{|l|c|c|c|c|c|c|c|c|c|c|}
\hline \multicolumn{1}{|c}{ Ocupação } & 2001 & 2002 & 2003 & 2004 & 2005 & 2006 & 2007 & 2008 & 2009 & 2010 \\
\hline $\begin{array}{l}\text { Atividades } \\
\text { relacionadas } \\
\text { ao Paraguai }\end{array}$ & 0 & 1 & 0 & 3 & 3 & 0 & 3 & 3 & 2 & 0 \\
\hline $\begin{array}{l}\text { Ativida d e s } \\
\text { relacionadas } \\
\text { ao Turismo }\end{array}$ & 0 & 1 & 2 & 2 & 0 & 0 & 1 & 0 & 3 & 0 \\
\hline $\begin{array}{l}\text { Atividades } \\
\text { relacionadas a } \\
\text { construção ci- } \\
\text { vil e a manu- } \\
\text { tenção predial }\end{array}$ & 3 & 4 & 5 & 5 & 17 & 8 & 7 & 7 & 2 & 5 \\
\hline $\begin{array}{l}\text { Atividades } \\
\text { vinculadas a } \\
\text { manufatura e } \\
\text { a indústria }\end{array}$ & 0 & 3 & 3 & 0 & 1 & 3 & 3 & 2 & 1 & 0 \\
\hline $\begin{array}{l}\text { Atividade } \\
\text { Rural }\end{array}$ & 0 & 1 & 2 & 1 & 0 & 2 & 2 & 0 & 0 & 0 \\
\hline $\begin{array}{l}\text { Prestação } \\
\text { de serviços, } \\
\text { liberais ou } \\
\text { autônomos }\end{array}$ & 3 & 5 & 6 & 7 & 5 & 7 & 4 & 3 & 2 & 1 \\
\hline Comércio & 1 & 0 & 0 & 1 & 0 & 2 & 1 & 0 & 2 & 0 \\
\hline $\begin{array}{l}\text { Serviço } \\
\text { Público }\end{array}$ & 0 & 0 & 0 & 1 & 0 & 0 & 0 & 0 & 2 & 0 \\
\hline Aposentado & 0 & 0 & 1 & 0 & 1 & 1 & 1 & 0 & 1 & 0 \\
\hline $\begin{array}{l}\text { Não sabe } \\
\text { ou não soube } \\
\text { responder }\end{array}$ & 1 & 1 & 3 & 2 & 0 & 3 & 6 & 4 & 2 & 5 \\
\hline
\end{tabular}

Fonte: Dados da Fundação Nosso Lar organizados pelo autor. 
Levando em consideração que parcela significativa das vítimas vivia unicamente com as suas mães (36\% dos jovens moravam apenas com a mãe, enquanto que $29 \%$ com o pai e a mãe), observar a inserção destas no mercado é representativo, pois abre a possibilidade de pensar sobre a necessidade do trabalho dos adolescentes na complementação de renda. Observa-se, por exemplo, que $34 \%$ das mães eram do lar, 20\% trabalhavam como domésticas, zeladoras ou nos serviços gerais, $10 \%$ atuavam no circuito turístico e $7 \%$ das mães desempenhavam alguma atividade vinculada ao Paraguai. Em 2007, ano com o maior número de homicídios de jovens até 17 anos de idade, $47 \%$ das vítimas moravam apenas com as mães, fato que reforça a necessidade de se observar com mais atenção o papel feminino no mercado de trabalho e na organização familiar.

Uma parcela reduzida dos pais das vítimas possuía carteira assinada nos períodos levantados pela pesquisa, $27,91 \%$ no ano de 2005 , 21,74\% em 2006, 27,91 em 2007, 23,81 em 2008 e 17,39\% em 2009. Concentrando-se exclusivamente nos números referentes às mães das vítimas, é possível observar que a grande maioria delas não estava atuando de maneira registrada, $58 \%$ no ano de $2005,74 \%$ em 2006 , $65 \%$ em 2007, 71\% em 2008 e $87 \%$ em 2009, reforçando a necessidade dos jovens em auxiliar na composição da renda familiar. Sobre isso, ressalta-se o elemento indicado anteriormente referente a baixa renda das vítimas e o fato de que a grande maioria das famílias e dos responsáveis das vítimas se considerarem pobres ou muito pobres.

A inserção das famílias no mercado de trabalho e as condições de vida dos jovens vitimados são alguns indicadores que apontam para as relações dos processos de empobrecimento e os crimes ocorridos. Todavia, eles ainda podem ser complementados com a análise da participação mais direta dos jovens nos mundos do trabalho e no interior das escolas. A necessidade de ajudar na composição da renda familiar e de conciliar trabalho e estudo são aspectos possíveis de serem identificados nas informações coletadas. Neste sentido, constata-se que $46 \%$ dos jovens eram economicamente ativos, desempenhado inúmeras atividades remuneradas, que podem ser visualizadas na tabela 03 . 
Tabela 03 - Ocupação dos Jovens Economicamente Ativos Vítimas de Homicídio

\begin{tabular}{|l|c|c|c|c|c|c|c|c|c|c|}
\hline \multicolumn{1}{|c|}{ Ocupação } & $\mathbf{2 0 0 1}$ & $\mathbf{2 0 0 2}$ & $\mathbf{2 0 0 3}$ & $\mathbf{2 0 0 4}$ & $\mathbf{2 0 0 5}$ & $\mathbf{2 0 0 6}$ & $\mathbf{2 0 0 7}$ & $\mathbf{2 0 0 8}$ & $\mathbf{2 0 0 9}$ & $\mathbf{2 0 1 0}$ \\
\hline $\begin{array}{l}\text { Atividades } \\
\text { relacionadas } \\
\text { ao Paraguai }\end{array}$ & $40 \%$ & $50 \%$ & $55 \%$ & $34 \%$ & $39 \%$ & $25 \%$ & $40 \%$ & $0 \%$ & $0 \%$ & $0 \%$ \\
\hline $\begin{array}{l}\text { Construção } \\
\text { civil e a } \\
\text { manutenção } \\
\text { predial }\end{array}$ & $0 \%$ & $0 \%$ & $11 \%$ & $11 \%$ & $0 \%$ & $23 \%$ & $10 \%$ & $15 \%$ & $0 \%$ & $17 \%$ \\
\hline $\begin{array}{l}\text { Manufatura } \\
\text { e a indústria }\end{array}$ & $0 \%$ & $0 \%$ & $0 \%$ & $33 \%$ & $17 \%$ & $20 \%$ & $10 \%$ & $8 \%$ & $40 \%$ & $0 \%$ \\
\hline $\begin{array}{l}\text { Atividade } \\
\text { Rural }\end{array}$ & $0 \%$ & $25 \%$ & $0 \%$ & $0 \%$ & $0 \%$ & $6 \%$ & $2 \%$ & $8 \%$ & $0 \%$ & $17 \%$ \\
\hline $\begin{array}{l}\text { Prestação de } \\
\text { serviços ou } \\
\text { autônomos }\end{array}$ & $40 \%$ & $25 \%$ & $22 \%$ & $22 \%$ & $18 \%$ & $10 \%$ & $18 \%$ & $16 \%$ & $40 \%$ & $17 \%$ \\
\hline $\begin{array}{l}\text { Comércio } \\
\text { Programas de } \\
\text { Inserção } \\
\text { Social }\end{array}$ & $0 \%$ & $0 \%$ & $12 \%$ & $0 \%$ & $26 \%$ & $10 \%$ & $20 \%$ & $8 \%$ & $0 \%$ & $34 \%$ \\
\hline $\begin{array}{l}\text { Não sabe ou } \\
\text { não soube } \\
\text { responder }\end{array}$ & $20 \%$ & $0 \%$ & $0 \%$ & $0 \%$ & $0 \%$ & $0 \%$ & $0 \%$ & $39 \%$ & $0 \%$ & $15 \%$ \\
\hline
\end{tabular}

Fonte: Dados da Fundação Nosso Lar organizados pelo autor.

Devido ao papel econômico que muitos dos jovens possuíam no interior de seus lares e também devido as suas próprias idades no momento em que morreram, o nível de escolaridade das vítimas tende a se concentrar no ensino fundamental concluído e incompleto. De forma geral, os índices indicam para existência de uma alta evasão e retenção, e também para uma necessidade eminente da efetivação da matricula no período noturno, fato que, como veremos, tem um forte impacto nos números de homicídios observados.

Tabela 04 - Escolaridade das Vítimas

\begin{tabular}{|c|c|c|c|c|c|c|c|c|c|c|}
\hline $\begin{array}{c}\text { Grau de } \\
\text { escolaridade } \\
\text { do adolescente }\end{array}$ & $\mathbf{2 0 0 1}$ & $\mathbf{2 0 0 2}$ & $\mathbf{2 0 0 3}$ & $\mathbf{2 0 0 4}$ & $\mathbf{2 0 0 5}$ & $\mathbf{2 0 0 6}$ & $\mathbf{2 0 0 7}$ & $\mathbf{2 0 0 8}$ & $\mathbf{2 0 0 9}$ & $\mathbf{2 0 1 0}$ \\
\hline Básica & $13 \%$ & $8 \%$ & $7 \%$ & $11 \%$ & $4 \%$ & $0 \%$ & $0 \%$ & $16 \%$ & $0 \%$ & $15 \%$ \\
\hline CEBEJA & $0 \%$ & $0 \%$ & $0 \%$ & $0 \%$ & $0 \%$ & $8 \%$ & $4 \%$ & $0 \%$ & $0 \%$ & $8 \%$ \\
\hline Classe especial & $0 \%$ & $0 \%$ & $0 \%$ & $0 \%$ & $0 \%$ & $0 \%$ & $4 \%$ & $0 \%$ & $0 \%$ & $0 \%$ \\
\hline Fundamental & $0 \%$ & $0 \%$ & $0 \%$ & $0 \%$ & $0 \%$ & $0 \%$ & $0 \%$ & $5 \%$ & $0 \%$ & $0 \%$ \\
\hline $\begin{array}{c}\text { Fundamental } \\
\text { Incompleto }\end{array}$ & $88 \%$ & $85 \%$ & $79 \%$ & $63 \%$ & $83 \%$ & $68 \%$ & $81 \%$ & $58 \%$ & $85 \%$ & $54 \%$ \\
\hline
\end{tabular}




\begin{tabular}{|c|c|c|c|c|c|c|c|c|c|c|}
\hline $\begin{array}{c}\text { Grau de } \\
\text { escolaridade } \\
\text { do adolescente }\end{array}$ & $\mathbf{2 0 0 1}$ & $\mathbf{2 0 0 2}$ & $\mathbf{2 0 0 3}$ & $\mathbf{2 0 0 4}$ & $\mathbf{2 0 0 5}$ & $\mathbf{2 0 0 6}$ & $\mathbf{2 0 0 7}$ & $\mathbf{2 0 0 8}$ & $\mathbf{2 0 0 9}$ & $\mathbf{2 0 1 0}$ \\
\hline Médio & $0 \%$ & $0 \%$ & $0 \%$ & $0 \%$ & $0 \%$ & $0 \%$ & $4 \%$ & $0 \%$ & $15 \%$ & $0 \%$ \\
\hline $\begin{array}{c}\text { Médio } \\
\text { Incompleto }\end{array}$ & $0 \%$ & $0 \%$ & $14 \%$ & $21 \%$ & $13 \%$ & $16 \%$ & $7 \%$ & $0 \%$ & $0 \%$ & $15 \%$ \\
\hline Superior & $0 \%$ & $0 \%$ & $0 \%$ & $0 \%$ & $0 \%$ & $0 \%$ & $0 \%$ & $0 \%$ & $0 \%$ & $0 \%$ \\
\hline NS/NR & $0 \%$ & $8 \%$ & $0 \%$ & $5 \%$ & $0 \%$ & $8 \%$ & $0 \%$ & $21 \%$ & $0 \%$ & $8 \%$ \\
\hline
\end{tabular}

Fonte: Dados da Fundação Nosso Lar organizados pelo autor.

O número de adolescentes mortos que eram matriculados na rede de ensino é abaixo da média do município, sinalizando para a importância da escola na diminuição dos crimes. No entanto, acreditamos que seria interessante observar a relação ou a proporção dos mortos não matriculados com o universo geral da população que está fora da escola, tal relação poderia oferecer dados mais precisos sobre a importância da escola na vida das crianças e adolescentes em situação de risco. Todavia, por meio dos dados existentes é possível afirmar que o número de vítimas aumenta conforme o período em que os jovens estudavam. Aqueles matriculados no período noturno são mais suscetíveis a estarem em situação de risco, pois representem o maior número de jovens vítimas.

Gráfico 02 - Turno de Freqüência nas Escolas.

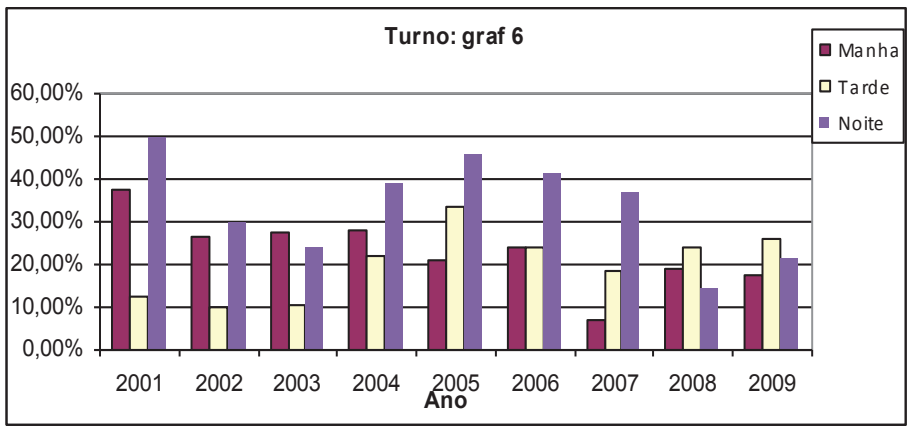

Fonte: Fundação Nosso Lar.

Embora o universo investigado seja composto por menores de idade, constata-se uma alta freqüência dos jovens no ensino ofereci166| Século XXI, Revista de Ciências Sociais, v.3, nº 2, p.155-181, jul./dez. 2013 ISSN: 2236-6725 
do a noite. Tal constatação abre espaço para duas colocações significativas: 1) nos anos onde existe um maior número de vítimas matriculadas no período diurno visualiza-se a diminuição no número de homicídios e; 2) os altos índices de matriculas no período noturno sinalizam para um problema no fluxo escolar e para uma suposta necessidade de conciliação dos estudos com o trabalho. Sobre o primeiro aspecto chama a atenção o fato dos anos de 2003, 2008 e 2009 terem os índices de vítimas matriculadas no período diurno superior aos demais anos e, ao mesmo tempo, apresentarem uma diminuição nos homicídios em relação ao momento imediatamente anterior.

Quanto ao segundo aspecto, os dados disponibilizados demonstram que a grande maioria das vítimas freqüentava o ensino de $5^{\circ}$ a $8^{\circ}$ série, confirmando a dificuldade de muitos no avanço nos estudos. $\mathrm{O}$ fato de estarem fora da idade adequada para os respectivos anos letivos talvez justifique o número de estudantes matriculados no período noturno, já que nem todos estavam inseridos no mercado de trabalho. Sobre isso, os dados disponibilizados são parciais, pois são limitados aos anos posteriores a 2005. No entanto, levando em consideração estudos que vem sendo realizados sobre o mercado de trabalho local, é possível afirmar a existência de uma gradativa e lenta diminuição da importância do Paraguai na absorção da força de trabalho juvenil na região. Ao longo da última década, observa-se um sucessivo aumento na intensidade da fiscalização e no combate ao contrabando e ao descaminho na fronteira do Brasil com o Paraguai, inibindo algumas práticas comuns no circuito sacoleiro ${ }^{1}$, como aquelas desempenhadas por laranjas ${ }^{2}$ e cigarreiros ${ }^{3}$.

Historicamente, tais ocupações sempre foram fundamentais no mercado de trabalho na região das três fronteiras, assimilando trabalhadores com os mais diferentes perfis, mas, principalmente,

\footnotetext{
${ }^{1} \mathrm{O}$ termo identifica as relações entre os diferentes sujeitos sociais responsáveis pelo percurso trilhado pelas mercadorias disponibilizadas no mercado paraguaio e que entram no Brasil de forma ilegal.

${ }^{2}$ Trabalhadores contratados informalmente para transportar determinada quantia de mercadoria em troca de um valor previamente determinado, que é conhecido como "cota". Esse serviço possui a função de auxiliar os sacoleiros na travessia dos produtos adquiridos pela Ponte da Amizade e pelos Postos de Fiscalização da Polícia e da Receita Federal.

${ }^{3}$ Trabalhador responsável exclusivamente pelo transporte de cigarros sobre a Ponte da Amizade. 167| Século XXI, Revista de Ciências Sociais, v.3, nº 2, p.155-181, jul./dez. 2013 ISSN: 2236-6725
} 
aqueles com maiores dificuldades de acesso ao mercado formal. Assim, muitos jovens encontravam no Paraguai a oportunidade de ingressar no mundo dos economicamente produtivos, assim como pessoas de maior idade que não conseguiam retornar ao mercado formal (Cardin, 2011a). Contudo, isso tudo vem passando por uma rápida transformação, visualizada na maior procura por cursos profissionais oferecidos pelas mais diferentes instituições sociais da cidade, no aumento da procura por empregos no setor de serviços, nas mutações ocorridas no funcionamento do circuito sacoleiro ou então na pouca relação das vítimas e de seus familiares com o comércio estabelecido com o país vizinho.

Durante a década de 1990 e começo dos anos 2000 Foz do Iguaçu se apresentava como o corredor principal de tráfico e contrabando no Brasil. Entretanto, ao longo da última década, com as mudanças do processo de fiscalização da Polícia e da Receita Federal na fronteira com Ciudad del Este vem se observando uma diminuição gradativa de práticas ilegais na região e a diminuição da utilização da força de trabalho de crianças e adolescentes em tais atividades. Uma consequência disso é a queda dos números que expressam a violência na região, como também da própria evasão escolar. Por outro lado, se os números de Foz do Iguaçu vêm apresentando melhoras, os indicadores das outras cidades banhadas pelo Lago de Itaipu e pelo Rio Paraná começam a preocupar.

Enquanto Foz do Iguaçu recebe maior atenção no que diz respeito à segurança pública e ao desenvolvimento social, os grupos que atuavam no circuito sacoleiro e no circuito mais vinculado ao narcotráfico estão se deslocando para outros municípios fronteiriços. Observa-se que cidades pequenas, com características rurais, estão apresentando índices significativos de violência e de evasão escolar. Municípios limítrofes com o Paraguai, como Terra Roxa e Guaíra, apresentam respectivamente $13,2 \%$ e $11,5 \%$ de evasão, números superiores a média brasileira, que é de $9,5 \%$. O fortalecimento dos fluxos de mercadorias entre as cidades brasileiras e paraguaias ampliam as possibilidades comerciais e, simultaneamente, a necessidade de cooptação de jovens aptos a trabalhar no transporte clandestino. 
Neste sentido, observar a participação das vitimas no mercado de trabalho também é algo representativo. Segundo as pessoas que responderam os questionários, $32,6 \%$ dos jovens vitimados entre os anos de 2001 e 2010 trabalhavam, enquanto 67,4\% não. Contudo, quando os mesmos entrevistados são questionados sobre as atividades realizadas pelos jovens os índices se modificam, passando para 39,4\% e $60,6 \%$ respectivamente. A justificativa encontra-se no fato de alguns dos responsáveis pelas vítimas não consideravam atividades relacionadas ao contrabando e ao tráfico de drogas como trabalho.

Os anos de 2005 e 2006 apresentam altas taxas de homicídios, 29 e 51 mortos respectivamente, e também os maiores índices de jovens trabalhadores. Por outro lado, a ano de 2007, que teve o maior número de jovens vitimados (54), apresenta o menor número de jovens trabalhando. Entre os 328 mortos no período estudado, 28 realizavam alguma atividade vinculada ao Paraguai. No ano de 2005, dos 18 jovens trabalhadores mortos, 07 atuavam no Paraguai, 06 destes desempenhavam a função de laranja. Em 2006, dos 16 mortos 03 eram laranja e, em 2007, dos 10 trabalhadores mortos 04 eram laranjas.

Jogar futebol, beber com os amigos, festar e dançar correspondiam as atividades de lazer preferidas dos jovens vitimados. $66,7 \%$ saiam e andavam com grupos de amigos, na grande maioria das vezes vizinhos da rua. $83,17 \%$ dos responsáveis não consideravam o jovem briguento ou "esquentado". O aprofundamento das questões com este perfil é marcada por um sucessivo aumento das perguntas "sem resposta". Quando questionados se os adolescentes davam trabalho para suas famílias, um pouco mais da metade dos questionários foram respondidos, mais precisamente 134, e quanto perguntados sobre o "tipo de trabalho" este número cai para 58.

Um pouco mais da metade das vítimas usavam algum tipo de droga, 36,95\% consumiam maconha, 25,89\% álcool e 19,42\% tabaco, sendo que $22,97 \%$ chegou a fazer algum tipo de tratamento contra o vício. $14,59 \%$ dos jovens tinham alguma arma de fogo e $58,82 \%$ deles já tiveram algum tipo de passagem pela polícia ou pelas instituições de recuperação de menores infratores. Tais números expressam distanciamentos entre as respostas, ao mesmo tempo em que 
mais de $80 \%$ dos jovens não eram considerados pelos responsáveis como problemáticos, quase $60 \%$ deles já tiveram algum tipo de problema com a justiça, sendo o roubo $(27,27 \%)$, porte de arma $(10,74 \%)$ e tráfico de entorpecentes $(9,09 \%)$ os delitos mais apontados.

Os motivos da morte são os mais diversos, mas agrupando as respostas nas categorias mais citadas observa-se que $17,76 \%$ dos jovens morreram por estarem na ocasião do crime envolvido em algum tipo de briga ou conflito sem motivos claros, 16,24\% foram vítimas de acerto de contas, $15,73 \%$ pelo envolvimento com drogas, $11,16 \%$ em crimes passionais e $6,09 \%$ em assaltos. Observa-se que as respostas necessariamente não são excludentes. Brigas sem motivos claros ou por motivos fúteis, acerto de contas e envolvimento com drogas podem ser em algumas ocasiões fatos correlacionados.

A maioria dos entrevistados não sabe informar sobre o autor do crime, mais precisamente 35,41\%; em $12,5 \%$ dos casos os autores morreram; em 16,66\% eles aguardam o julgamento; em 6,94\% eles encontram-se presos e; em $27,77 \%$ eles nunca foram encontrados. Tais indicadores explicitam as dificuldades do sistema policial e judiciário em resolver e aplicar adequadamente as leis nos casos de homicídio onde os jovens são vitimados. Isso ajuda a entender o fato de que $26,42 \%$ das famílias das vítimas terem se mudado e de que $39,28 \%$ das famílias terem se sentido ameaçadas após o incidente.

Quando os entrevistados foram indagados sobre o que poderia ter sido feito para evitar o ocorrido nenhum dos depoentes assinalaram para o aumento ou melhoria na segurança pública, muito menos para questões vinculadas ao mercado de trabalho e ao modelo de desenvolvimento econômico adotada na região. De modo geral, as respostas se amarram a três questões: 1) a vítima deveria ter mudado algum aspecto de sua conduta, como, por exemplo, voltado a estudar, a trabalhar, parar de beber, usar drogas, etc.; 2) a vítima deveria escutar mais sua família e responsáveis ou ter ficado mais tempo em casa e; 3 ) ter ficado em sua cidade de origem ou ter ido embora de Foz do Iguaçu. 


\section{A FRONTEIRA}

As entrevistas realizadas neste estudo e também em uma investigação anterior (Cardin, 2011c) indicam que a fronteira internacional se configura como uma variável importante nas práticas sociais dos jovens. A configuração das relações sociais e comerciais existentes, principalmente, na região da fronteira do Brasil com o Paraguai, apresenta-se como um aspecto relevante para a compreensão do fenômeno de interesse. Em um primeiro lugar ela gera e ao mesmo tempo é dependente de um conjunto de ocupações e relações flexíveis e muitas vezes precárias que garantem a circulação de pessoas, mercadorias e capitais. Por fim, ela possibilita e se alimenta de práticas de consumo particulares, marcadas por fluidez, pirataria e clandestinidade.

Nas regiões de fronteira é comum o constante e circular fluxo de trabalhadores e mercadorias derivado ou possibilitado pelas especificidades políticas, econômicas, tributarias e sociais existentes em cada um dos países limítrofes, em diversas realidades observa-se a existência de um transito originado das diferenças. Pessoas que buscam se aproveitar organizando estratégias para utilizar de forma instrumental as fronteiras, seja na busca de lazer ou da própria sobrevivência. E conforme a distância ou tamanho das diferenças existente entre os países mais atrativo se torna o "cruzamento das fronteiras", como os casos da imigração ilegal dos latino-americanos para os Estados Unidos, dos africanos na Europa e do tráfico de drogas, armas, animais e mercadorias ilegais nas regiões fronteiriças.

Em todos os casos, as práticas são originadas de redes e grupos sociais que visam organizar os mecanismos e estratégias de aproveitamento das possibilidades conjunturais que aparecem nas regiões de fronteiras. Alguns exemplos podem ser encontrados nas ações dos coiotes, das máfias, dos grupos de narcotraficantes e dos diferentes circuitos sociais que disputam espaço e concorrem pelos melhores lugares e canais de circulação na busca da ampliação do lucro. Quanto mais dependente a economia regular de uma cidade for das práticas ilegais e clandestinas, mais as redes e os grupos sociais desenvolvem a capacidade de cooptar os jovens e a população vulnerável. 
O desenvolvimento destes grupos é vinculado e altamente dependente da relação que eles estabelecem com o Estado e com os demais sujeitos sociais que utilizam e vivenciam a mesma realidade. Nos conflitos e articulações com os aparelhos de fiscalização e repressão do Estado e também com os grupos concorrentes se desenham as paisagens das fronteiras e, principalmente, a formas que adquirem o tráfico, o contrabando e o descaminho nas mais diferentes regiões. Os espaços são disputados no sentido de se buscar as melhores posições e os esforços são direcionados para conquista ou para a construção do monopólio de determinado setor, ramo ou nicho econômico.

López, investigando a fronteira dos Estados Unidos com o México destaca que:

En las fronteras pueden existir masivos intercambios de bienes y servicios, de personas y de vehículos, y una economía que crece aprovechando precisamente sus diferencias y sus complementariedades, como es evidente. Pero también existe un referente legal, diferenciando por las fronteras, que regularmente también forma parte de las complementariedades. Las diferencias de marcos jurídicos y de estructuras gubernamentales abren en la frontera la posibilidad de crear "espacios de escape" para determinados actores o prácticas. En la naturaleza de la frontera se abre esta posibilidad que se resume com una frase: lo ilegal de un lado puede ser legal del outro (López, 2011, p. 165)

Tal situação, criada pelas particularidades legislativas de cada país, permite práticas simples. Nos Estados Unidos, por exemplo, é proibido o consumo de bebida alcoólica por jovens menores de 21 anos. Por outro lado, no México é permitido o consumo a partir dos 18 anos. Com isso, torna-se comum as cidades fronteiriças mexicanas receberem muitos jovens norte-americanos entre 18 e 20 anos com o propósito de ingerir legalmente álcool nos bares e restaurantes mexicanos (López, 2011, p. 165). Todavia, este ponto esponjoso, onde as pessoas transitam por leis, identidades e culturas diferentes, pode criar situações muito mais complexas, pois cada país possui suas próprias regras de acesso e uso de drogas e armas, por exemplo. 
Neste sentido, constata-se que no ano de 2008 ocorreram 74 homicídios a cada 100 mil habitantes na fronteira México-Estados Unidos (Carrión, 2011, p. 89).

As regiões de fronteira marcadas por maior porosidade, devido às características geográficas ou até mesmo devido à fragilidade dos aparelhos estatais de controle aduaneiro, tendem a apresentar focos maiores de tensão. A fronteira colombiana explicita isso ao possuir altos números de homicídios e também uma circulação ilegal de grupos paramilitares que desconsideram as fronteiras nacionais em seus deslocamentos pela selva amazônica. Na fronteira Colômbia/ Venezuela constata-se um número de 68 mortos a cada 100 mil habitantes e 51 mortos no seu limite com o Brasil (Carrión, 2011, p.89). Em ambos os casos, os índices estão muito longe dos aceitáveis e são justificados por diferentes elementos causais que perpassam pelas disputas territoriais entre latifundiários, mineradores e populações ameríndias, como também pelos conflitos entre narcotraficantes.

Nestes casos, crimes relacionados ou definidos como acerto de conta, execução sumária, queima de arquivo, tendem a denunciar a existência de disputa de posições ou de luta por controle de território. Logo, as regiões de maior dinamismo nos fluxos e com a maior quantidade de atores envolvidos tendem a serem as localidades mais violentas, pois são e estão constantemente em disputa. A fronteira de Foz do Iguaçu com Ciudad del Este configura-se como uma região de grande destaque no Brasil, pois possuem as maiores cidades limítrofes dos dois países, sendo representativas econômica e socialmente para suas nações. Consequentemente, apresenta maiores possibilidades e oportunidades para suas respectivas populações, independente das possíveis definições jurídicas ou criminais.

As formas de intervenção do Estado também devem ser consideradas na busca do entendimento da geografia e organização dos grupos nas regiões de fronteira. Um Estado mais permissivo garante a existência de uma maior quantidade de grupos e de formas de utilização das fronteiras, enquanto um Estado mais repressivo e fiscalizador inibe a formação dos grupos e fortalece o estabelecimento ou nascimento de monopólios ou, em outros termos, de grupos específicos que 
controlam de forma mais agressiva determinado espaço econômico e social. Assim, as alterações no modo de ação dos Aparelhos do Estado são acompanhadas de mudanças na organização dos grupos sociais. Em resumo, o modus operandi daqueles que vivem da fronteira define e é definido pelas estratégias adotadas pela polícia e receita federal brasileira no combate ao contrabando e ao descaminho.

$\mathrm{O}$ contrabando e o descaminho estão presentes na fronteira do Brasil com o Paraguai desde o momento em que tais regiões sofreram com o processo de demarcação e estabelecimento dos limites internacionais. Contudo, os mecanismos desenvolvidos para tais práticas se alteraram ao longo da história, da mesma forma que os produtos transportados clandestinamente. Em um primeiro momento, o Rio Paraná era ocupado por grandes embarcações carregadas ilegalmente de madeira e erva-mate, posteriormente o café começou ocupar a estrutura existente. Com a crise no mercado destes produtos, as dificuldades econômicas da região são acentuadas, inicia-se então um contrabando maior de vivendas, promovido em menor escala por pessoas isoladas, como o trabalho de formiguinhas.

Com a construção da Ponte da Amizade, ligando os dois países, este tipo de atividade de subsistência é facilitado. Todavia, neste mesmo período é criado a zona de livre comércio em Ciudad del Este, garantindo um incremento no perfil das mercadorias contrabandeadas. Os produtos para o consumo do lar, principalmente alimentos, começam a perder espaço para eletroeletrônicos, brinquedos, bebidas e perfumes. A diferença dos valores dos produtos disponibilizados pelo mercado paraguaio em relação àqueles encontrados no Brasil gradativamente fomentou o surgimento do circuito sacoleiro, ou seja, de uma rede de trabalhadores com o objetivo de comprar, transportar e revender as mercadorias negociadas em Ciudad del Este.

O fortalecimento de tais práticas garantiu a absorção de parte significativa da força de trabalho iguaçuense durante algumas décadas, mas, por outro lado, também exigiu do governo brasileiro uma maior atenção no sentido de evitar a evasão fiscal e a entrada de produtos ilegais no território brasileiro. Neste sentido, a expansão do circuito sacoleiro foi acompanhada pelo desenvolvimento de di- 
ferentes estratégias de combate ao contrabando e ao descaminho por parte do governo federal. A relação entre estes dois movimentos alimentou sucessivamente o nascimento de outras formas de transporte e circulação das mercadorias, exigindo constantes adaptações nas práticas que, em determinados momentos, envolvia um grande contingente populacional e, em outros, tornava-se mais restrito.

As mutações sofridas pelo circuito sacoleiro e as suas relações conflitivas com a receita e a polícia federal vinculavam-se a momentos de crescimento e recessão econômica na região, desenhando com linhas muito finas o mercado de trabalho na fronteira, assim como as suas demais dimensões sociais. Em resumo, as oscilações comerciais entre os países estabelecem parte significativa das dinâmicas existentes na região. Porém, quando se fala de tal mercado, não está sendo pautada as relações entre governos e, muito menos, o comércio internacional supostamente possibilitado pela globalização e mundialização de capitais, mas as práticas, as experiências, os modos de viver promovidos no interior de um mercado popular ou, como denomina Gustavo Lins Ribeiro (2009), de uma globalização vista de baixo.

\section{CONSIDERAÇÕES FINAIS}

Sem embargo, a relação entre as cidades limítrofes na região das três fronteiras é fundamental para desenvolvimento local e para a compreensão das modificações nos índices de violência apresentados. Enquanto existia uma alta aderência do mercado iguaçuense com o comércio existentes em Ciudad del Este parte significativa da população tinha sua renda principal vinculada ao circuito sacoleiro. As relações existentes ofereciam inúmeras possibilidades de inserção e sobrevivência, principalmente durante a década de 1990 e começo do século XXI. Todavia, com a reorganização do circuito na última década, aquela relação que era explícita começa a ser mais dissimulada. Gradativamente vai ocorrendo um processo de desagregação do cotidiano de Foz do Iguaçu com o comércio paraguaio e uma reorganização do mercado e das relações sociais. 
Os anos de 2004, 2005, 2006 e 2007 representam períodos de adaptação da realidade local à nova conjunta da tríplice fronteira, ou seja, uma readequação à fiscalização da Receita, da Polícia Federal e do próprio funcionamento do circuito sacoleiro. Uma hipótese para o entendimento da diminuição dos crimes contra crianças e adolescentes nos últimos anos se encontra exatamente neste ponto. Acredita-se que ao longo da última década a região vivenciou e ainda vivencia modificações nas suas organizações sociais e na sua forma de se relacionar com as fronteiras, aspecto que interferiu diretamente dos números apresentados. Baseando-se exclusivamente nas variáveis apresentadas, sem realizar uma avaliação mais geral e sem indicar possíveis elementos que podem interferir nas relações, mas que neste momento não podem ser comprovados, destaca-se a importância da questão econômica.

A porcentagem dos jovens inseridos no mercado de trabalho, a informalidade das ocupações tidas pelos pais das vítimas, o nível de renda das famílias que fazem com que a grande maioria delas se considerem pobre ou muito pobre, configuram-se como importantes aspectos esclarecedores. Enquanto outras variáveis disponibilizadas pela pesquisa apresentam grandes oscilações, o nível de renda e de trabalho é homogêneo e determinante. É ele que coloca os jovens em situação de risco, é ele que limita o espaço de manobra e as opções de escolha que os sujeitos podem ter durante suas trajetórias de vida. Como não fosse suficiente o processo de empobrecimento levar um imenso contingente de pessoas para um constante estado de vulnerabilidade, vivemos em um mundo que, cada vez mais, condena a pobreza e a criminaliza, promovendo uma verdadeira inversão de valores, onde as vítimas se tornam os culpados (Wacquant, 2001). 
Gráfico 03 - Número de Mortes.

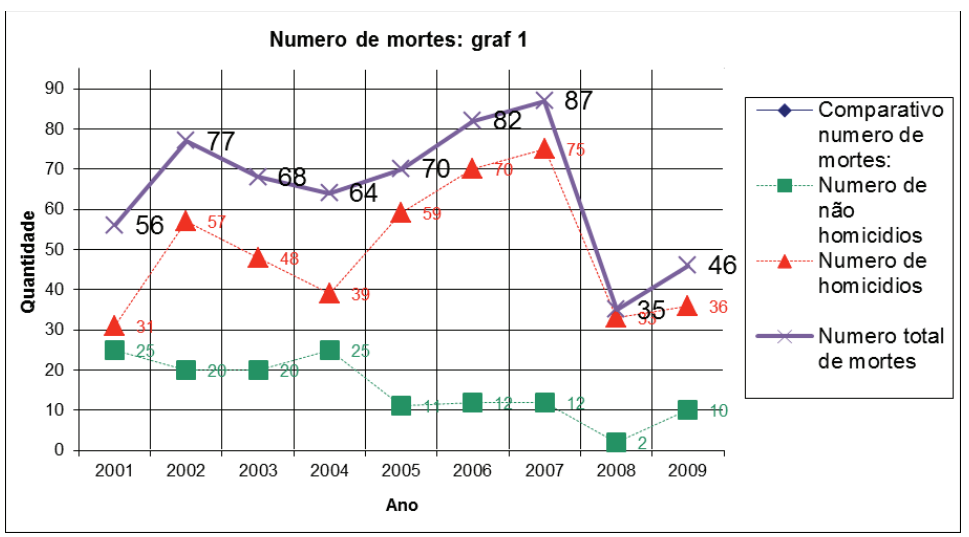

Fonte: Fundação Nosso Lar

Observando o Gráfico 03, visualiza-se um movimento gradativo de ascensão da violência, que chega em 2007 no seu ápice, seguido de uma queda significativa. O período de crescimento da violência corresponde ao momento de mudança nas formas de atuação e de combate ao contrabando e descaminho por parte dos Aparelhos do Estado, é um momento de "choque de gestão", exigindo uma rápida readequação dos grupos à nova realidade, respingando nos índices de violência da região. A partir de 2008, observa-se uma diminuição paulatina dos números de homicídio em Foz do Iguaçu e também da evasão escolar. Ambos os fenômenos são acompanhados de uma maior procura de trabalho na Agência dos Trabalhadores e no Sistema Nacional de Emprego.

Por outro lado, a violência e a evasão escolar encontram-se em crescimento no restante da extensão da fronteira do Brasil com o Paraguai. Em um primeiro momento, acreditava-se que os grupos criminosos que agiam na fronteira de Foz do Iguaçu e Ciudad del Este estavam se deslocando para outros pontos da fronteira, disputando novos territórios e cooptando adolescentes para atuarem no transporte de mercadorias, drogas e armas. Neste sentido, se pensava que a diminuição das mortes em Foz do Iguaçu estaria relacionada ao seu aumento nas cidades vizinhas, porém tal afirmação ainda é especulativa e precisa ser mais bem fundamentada. 
Contudo, aprofundando as discussões sobre a relação entre o contrabando e os processos de escolarização (Cardin, 2013), observei que o problema é um pouco mais complexo do que vinha sendo noticiado pela mídia ${ }^{4}$. Em linhas gerais, a relação entre as possibilidades oferecidas pelo contrabando e a evasão escolar não ocorre de uma maneira muito simples. Durante a realização de pesquisas de campo na fronteira do Brasil com o Paraguai, observou-se que: 1) os jovens consideram a escola "pouco atrativa"; 2) que o número de evasão escolar varia conforme a localidade do colégio e o contexto social onde ele está inserido, permitindo afirmar que não é o contrabando que incentiva a evasão, mas a pobreza; 3 ) e, por fim, o estilo de vida oferecido pelo contrabando é mais dinâmico e atrativo para os jovens do que as atividades rotineiras oferecidas pelo mercado de trabalho formal.

Partindo destas observações, é possível afirmar que os novos dinamismos da fronteira, possibilitados pela expansão do capital e do circuito sacoleiro para outros pedaços da fronteira do Brasil com o Paraguai, fomentou uma "formatação econômica, cultural e política mais atrativa que a anteriormente existente, que tinha características mais estáveis, rígidas e muitas vezes carregadas de tradições rurais" (Cardin, 2013). Neste sentido, conclui que:

A nova situação vem alimentando um conflito de padrões culturais, onde os jovens são suscetíveis não a cooptação por grupos de contrabandistas ou traficantes, mas pelas possibilidades abertas durante o processo de acumulo de capital social e econômico que estas relações podem permitir. Em uma conjuntura, onde o mercado de trabalho legal oferece uma renda limitada e uma carga horaria de trabalho rígida, a possibilidade de obter uma maior renda em um ritmo diferenciado é atrativa. E dentro desta mesma lógica, a manutenção de jovens no interior de salas de aula que colocam como meta para o aluno a inserção naquele mercado de trabalho estático e sem graça ou naquela sociedade tradicional, que é pensada, repensada e reafirmada pelos modelos tradicionais de organização da educação, é um tiro no próprio pé.

\footnotetext{
${ }^{4}$ Ver: http://www.gazetadopovo.com.br/vidaecidadania/conteudo.phtml?tl=1\&id=1285852\&tit=E scolas-na-fronteira-perdem-alunos-para-o-contrabando-e-o-narcotrafico-
}

178| Século XXI, Revista de Ciências Sociais, v.3, nº 2, p.155-181, jul./dez. 2013 ISSN: 2236-6725 
Para finalizar, destaca-se que o entendimento da violência contra os jovens perpassa pela observação crítica da situação econômica das vítimas, dos hábitos de consumo e de sociabilidade da população, da atuação do sistema de justiça e, por fim, do contexto que envolve a realidade investigada, com destaque para o impacto que os dinamismos da fronteira exerce nas práticas sociais adotadas pelos jovens que habitam o extremo oeste paranaense. Em síntese, a fronteira e seus conflitos, suas oportunidades e possibilidades, geram um universo rico, que agrega elementos decisivos na trajetória dos jovens mortos ao longo da última década e que precisam ser considerados no desenvolvimento de políticas públicas de segurança e também para a juventude.

\section{REFERÊNCIAS}

ANDRADE, Luciano. Análise da Distribuição Espacial dos Homicídios Juvenis em um Município Brasileiro de Tríplice Fronteira no Período de 2000 a 2007. 2009. Dissertação (Mestrado em Enfermagem) - Programa de Pós-Graduação em Enfermagem, Universidade Estadual de Maringá, Maringá.

CARDIN, Eric Gustavo. O Novo Mundo do Trabalho e o Perfil dos Trabalhadores Informais de Foz do Iguaçu (2002 - 2007). In: CARDIN, Eric Gustavo; DEBALD, Blasius; SOUZA, Keila Rodrigues de. Região \& Desenvolvimento: Estudos Temáticos Sobre o Extremo Oeste do Paraná. Foz do Iguaçu: UNIAMÉRICA, p. 07-26, 2009a.

. Globalização e Desenvolvimento Regional na Tríplice Fronteira. Revista Ciências Sociais UNISINOS, Vol. 45, p.162-170, 2009 b.

. Expansão do Capital e Desenvolvimento Regional: Foz do Iguaçu entre o Legal e o Ilegal. Revista Ideação. Cascavel: EDUNIOESTE, Vol. 12, no.01, pp. 01-117, 2010.

- Laranjas e Sacoleiros na Tríplice Fronteira: um estudo da precarização do trabalho no capitalismo contemporâneo. Cascavel: EDUNIOESTE, 2011a. . Trabalho e Organização dos "Barqueiros" na Fronteira do Brasil com o Paraguai. In: BOSI, Antônio; VARUSSA, Rinaldo. Trabalho 
e Trabalhadores na Contemporaneidade: Diálogos Historiográficos. Cascavel: EDUNIOESTE, 2011b.

A Expansão do Capital e as Dinâmicas da Fronteira. Tese (Doutorado em Sociologia) Programa de Pós-Graduação em Sociologia, Universidade Estadual Paulista "Julio de Mesquita Filho", Araraquara, SP, 2011c.

. O Trabalho Infantil e o Contrabando de Cigarro na Fronteira de Guaíra/Brasil e Salto del Guaírá/Paraguai. In: Anais da Xo Reunión de Antropología do Mercosur. Córdoba/Argentina: RAM, 2013

CARRIÓN, Fernando. En el límite de la vida: "la violencia fronteriza". In: CARRIÓN, Fernando; ESPÍN, JOHANNA. Relaciones Fronterizas: Encuentros y Conflitos. Quito: FLACSO, 2011, p.77-117.

FOZ DO IGUAÇU. Dados Socioeconômicos de Foz do Iguaçu. In: $<$ http://www.fozdoiguacu.pr.gov.br/Portal/VisualizaObj. aspx?IDObj=12845>

KLEINSCHMITT, Sandra Cristiana. Homicídios na Fronteira Internacional entre o Brasil e o Paraguai: considerações sobre Foz do Iguaçu e a Região Metropolitana de Ciudad del Este. Dissertação (Mestrado em Ciências Sociais) Programa de Pós-Graduação em Ciências Sociais, Universidade Estadual do Oeste do Paraná, Toledo, PR, 2012.

LÓPEZ, Tonatiuh Guillén. Fronteras y seguridade: la experiência entre México y Estados Unidos. In: CARRIÓN, Fernando; ESPÍN, JOHANNA. Relaciones Fronterizas: Encuentros y Conflitos. Quito: FLACSO, 2011, p.159-169.

SOUZA, Rosane Cleide de. O serviço social e a política de habitação. In: <http://www.uniamerica.br/blog/servico_social/projetos_de_ extensao/o_servico_social_e_a_politica_de_habitacao $>$. Acesso em: 20 out. 2011.

RIBEIRO, Gustavo Lins. A Globalização Popular e o Sistema Mundial Não-Hegemônico. Ou, de Guangdong a Caruaru. RBSE, Vol. 8, n²4, p. 510-522, 2009.

ZALUAR, Alba. Qualidade de dados: políticas públicas eficazes e democracia. Integração Perversa. Rio de Janeiro: Editora FGV, 2004. (pp. 13-22).

WACQUANT, Loic. As Prisões da Miséria. Rio de Janeiro: Jorge Zahar 
Editor, 2001.

WAISELFISZ, Julio Jacobo. Mapa da Violência 2010: Anatomia dos Homicídios no Brasil. São Paulo: Instituto Sangari, 2011.

Recebido: 08/03/2013. Aprovado com indicação de alterações: 31/10/2013.

Aprovado: 21/11/2013. 